\title{
ANALISIS STRATEGI PENGEMBANGAN PEMASARAN DAN NILAI TAMBAH TIWUL INSTAN
}

\author{
Zulkarnain ${ }^{1}$ \\ ${ }^{1}$ Sekolah Tinggi Ilmu Pertanian (STIPER) Dharma Wacana Metro \\ e-mail: zulfadhilalzabir@gmail.com
}

\begin{abstract}
The agricultural sector occupies a strategic position compared with other sectors. It is evident from its role in employment and contribution to gross domestic product. Tiwul has high economic value because of its relatively high nutrient content. Therefore, the advantage of Tiwul as a substitute for rice can be socialized (Subahar, 2004). The purpose of this study was to analyze strategy of marketing and instant Tiwul added value development in Wonosari District, Pekalongan, of East Lampung regency. The method used in this research was SWOT analysis and added value analysis. Respondents were selected intentionally (purposive) in Wonosari Pekalongan District of East Lampung regency with a sample of 20 respondents composed of 10 producers and 10 traders in addition to direcly observe the added value of instant Tiwul by conducting interviews with KWT Tani home industry. The results of this study indicated that the strategies used to improve the marketing of instant Tiwul in Wonosari District of East Lampung regency Pekalongan showed coordinates of $(0.34 ;-0.50)$ in which the coordinates entered quadrant II, that although facing a variety of threats, the company still has iternal strength. The strategy that should be applied is to take advantage of long-term opportunities by way of diversification strategy (product / market). Instant Tiwul marketing in Wonosari District of Pekalongan has the strength in term of Tiwul production quality and increasing amount of production, which can be used to counter the threat. Added value for producers of instant Tiwul per production in East Lampung district is Rp 9450.00.
\end{abstract}

Keyword: Strategy, Development and Marketing, Instant Tiwul, Added Value

\section{Pendahuluan}

Sektor pertanian merupakan sektor yang paling penting di hampir semua negara berkembang seperti menyediakan bahan baku industri, menyediakan lapangan kerja, peningkatan penerimaan devisa, dan peningkatan pendapatan masyarakat tani (Zulkarnain, 2010). Peranan sektor pertanian merupakan kontribusi yang sangat besar terhadap Produk Domestik Regional Bruto (PDRB). Subsekor tanaman pangan/hotikultura merupakan subsektor yang mempunyai prospek yang baik di masa mendatang sehingga dapat diandalkan memajukan perkonomian Indonesia (Ibrahim dkk, 2003). Tanaman pangan merupakan komoditas strategis bagi bangsa Indonesia. Komoditas tanaman pangan yang penting adalah ubi kayu. Data produktivitas ubi kayu di Indonesia pada Tabel 1.

Berdasarkan Tabel 1 menunjukkan bahwa luas panen dan produksi ubi kayu mengalami fluktuasi. Hal ini antara lain dikarenakan banyaknya penyakit yang menyerang sehingga terjadi gagal panen. Meskipun demikian, menurut Badan Pusat Statistik (2015) Propinsi Lampung merupakan salah satu daerah pusat penghasil singkong di Indonesia.

Provinsi Lampung berpotensi besar untuk menjadi pemasok ubi kayu. Kondisi ini mendorong petani untuk memperluas areal tanamnya guna meningkatkan produksi ubi kayu. Produksi ubi kayu di Propinsi Lampung pada tahun 2010 - 2014 mengalami fluktuatif (Badan 
Pusat Statistik, 2015). Produksi ubi kayu di Kabupaten Lampung Timur mengalami kenaikan dari tahun ke tahun. Produksi ubi kayu di Kabupaten Lampung Timur menduduki peringkat ke 4 (empat) sebesar 1.433.094 ton pada tahun 2014. Sedangkan produksi ubi kayu tertinggi yakni pada Kabupaten Lampung Tengah yakni 2.401.090 ton pada tahun 2014 (Badan Pusat Statistik, 2015).

Tabel 1. Luas Panen dan Produksi Ubi Kayu Tahun 2011- 2015

\begin{tabular}{clccc}
\hline No. & Tahun & Luas Panen $(\mathrm{Ha})$ & Produksi (Ton) & Produktivitas (Ton/Ha) \\
\hline 1. & 2011 & 1.040 .025 & 23.936 .384 & 230,01 \\
2. & 2012 & 980.960 & 21.801 .415 & 222,24 \\
3. & 2013 & 1.000 .602 & 23.436 .384 & 234,22 \\
4. & 2014 & 1.044 .966 & 23.936 .921 & 229,07 \\
5. & 2015 & 1.184 .696 & 24.044 .025 & 242,96
\end{tabular}

Sumber: Badan Pusat Statistik, 2015

Permasalahan yang dihadapi dalam pengembangan ubi kayu di Indonesia adalah rendahnya penerapan teknologi, terbatasnya modal usaha tani, sempitnya lahan skala usaha, terjadinya fluktuasi produksi dan harga pada panen raya, sifat ubi kayu yang mudah rusak. Hal ini menyebabkan petani melakukan inovasi-inovasi agar ubi singkong saat harga pada panen raya memiliki nilai jual yang tinggi. Salah satu olahan pangan yang memiliki nilai jual tinggi adalah tiwul. Tiwul merupakan makanan tradisional yang menjadi makanan pokok alternatif pengganti nasi beras. Berbeda dengan nasi putih atau beras yang berasal dari padi, tiwul memiliki ciri tersendiri, sedikit menggumpal dan berwarna kekuningan, kecoklatan, kehitaman, bahkan ada yang berbentuk putih menyerupai beras dengan aroma yang kuat. Tiwul yang biasa dijumpai yaitu berbentuk seperti butiran-butiran beras berwarna coklat kehitaman.

Kebutuhan pokok manusia terhadap beras sebagai makanan pokok yang bergizi tinggi, dan sudah menjadi sebuah budaya pangan yang pakem di dalam kehidupan. Namun, dengan meningkatnya kebutuhan pangan masyarakat akan beras menjadikan persediaan beras menipis akibat gagal panen dan harga jual yang tinggi. Hal demikian menjadikan masyarakat beralih ke pangan alternatif yaitu tiwul. Tiwul mempunyai nilai ekonomi tinggi karena kandungan gizinya yang relatif besar. Karena itu, pemanfaatnnya untuk dijadikan pengganti beras dapat dimanfaatkan oleh dimasyarakatkan (Subahar, 2004). Walaupun bukan makanan pokok masyarakat, akan tetapi tiwul memiliki prospek yang baik untuk dikembangkan di wilayah nusantara, terutama bila diusahakan secara intensif berpola agribisnis (Rukmana, 1998).

Tabel 2. Produksi Usaha Tiwul Di Desa Wonosari Kecamatan Pekalongan Kabupaten Lampung Timur 2011 - 2015

\begin{tabular}{crrr}
\hline Tahun & Produksi $(\mathrm{Kg})$ & Pertumbuhan $(\%)$ & \\
\hline 2011 & 9.560 & - \\
2012 & 9.729 & 2,27 \\
2013 & 10.440 & 2,00 \\
2014 & 10.620 & 3,41 \\
2015 & 10.800 & 3,90
\end{tabular}

Sumber: Data Hasil Prasurvey, 2016

Berdasarkan Tabel 2 menunjukkan bahwa produksi usaha tiwul di Desa Wonosari Kecamatan Pekalongan Kabupaten Lampung Timur mengalami peningkatan dari tahun ke tahun. Pada tahun 2011 hanya $9.560 \mathrm{~kg}$ sedangkan pada tahun 2015 meningkat 3,90\% menjadi $10.800 \mathrm{~kg}$. Peningkatan tersebut dikarenakan permintaan konsumen yang terus meningkat sebab tiwul bermanfaat bagi penderita diabetes. Selama itu, tiwul instan untuk kebutuhan lokal saja yakni hanya di pasarkan ke Pekalongan, Kota Metro, Kota Gajah dan Bandar Jaya. Daerah-daerah tersebut telah menjadi sentra untuk pemasaran tiwul instan. Meski potensi besar, saat ini sebagian besar warga tidak lagi mengenal pangan lokal di daerahnya. Bahkan berdasarkan

JoFSA Vol. 1, No. 1, April 2017 : 1-11 
sebuah survey, pangan hanya dikenal oleh $20 \%$ masyarakat. Tanpa upaya berarti, pangan lokal yang potensial ini akan terus terlupakan.

Produksi tiwul instan adalah usaha mengolah singkong untuk dijadikan bahan tiwul dan nilai tambah dari pengelolaan tiwul instan. Untuk menjaga kualitas produksi yang berkualitas tinggi, pemasaran yang bagus dan mendatangkan kesejahteraan bagi berbagai pihak, maka sangat diperlukan kerja yang profesional. Keputusan para petani untuk beralih menjadi industri tiwul dikarenakan harga dari singkong ini cenderung menurun, berbeda dengan tiwul yang harganya relatif tinggi sehingga memiliki nilai tambah dan jumlah permintaan pasar semakin meningkat mengingat kandungan yang ada dapat menjadi pengganti beras bagi penderita diabet. Dari pada itu, produksi singkong segar tidak dapat disimpan terlaku lama yaitu hanya berkisar antara empat sampai lima hari (Soetarto,E.S 2008). Oleh karena itu dibuatlah tiwul. Namun sayangnya, terdapat berbagai kendala dalam memasarkan tiwul dikarenakan makanan ini kurang digemari oleh masyarakat dan tidak dijual ke semua toko. Padahal, tiwul memiliki Glikemik sebesar 29 (Verawati dkk, 2011) yang berarti lebih aman dikonsumsi bagi penderitaan diabetes dibanding nasi dan dilihat dari aspek ekonomi, tiwul instan memiliki nilai tambah sehingga akan meningkatkan pendapatam rumah tangga.

Minimnya pengetahuan tentang manfaat tiwul menjadikan tiwul belum begitu di nikmati oleh para konsumen, ini menjadikan permintaan tiwul belum maksimal, sehingga perlu dipertahankan eksistensi usahanya, strategi pemasaran yang baik akan sangat membantu meningkatkan permintaan tiwul di pangsa pasar serta menciptakan nilai tambah (keunggulan) yang mampu menghasilkan laba yang berkelanjutan. Oleh karena itu, pengusaha home industri dirasa perlu menetapkan strategi pemasaran yang tepat untuk mendukung perkembangan petani di masa yang akan datang. Berdasarkan permasalahan yang ada, maka dalam penelitian ini dapat dirumuskan sebagimana identifikasi masalah adalah "Bagaimana analisis strategi pengembangan pemasaran dan nilai tambah tiwul instan di Desa Wonosari Kecamatan Pekalongan Kabupaten Lampung Timur?

\section{Metode}

Lokasi penelitian dipilih secara sengaja (purposive) yaitu di Desa Wonosari Kecamatan Pekalongan Kabupaten Lampung Timur.Tempat penelitian ini dipilih karena disini terdapat industri rumah tangga yang berproduksi tiwulinsta masih memerlukan strategi pemasaran.Sistem pemasaran dilakukan apabila ada pesanan dari agen tiwul kemudian baru melakukan produksi tiwul instan. Waktu penelitian dilaksanakan pada bulan Desember 2016. Metode pengumpulan data yang terkait dengan populasi adalah masyarakat di Desa Wonosari Kecamatan Pekalongan yang berprofesi sebagai pengusaha tiwul instan, agen dan konsumen. Jumlah sampel penelitian di Desa Wonosari Kecamatan Pekalongan adalah sebanyak 20 responden yang terdiri dari 10 orang produsen dan 10 orang pedagang.Pengambilan sampel diambil dengan caranon probability sampling yakni teknik snowball sampling (Sugiyono, 2009). Namun, apabila peneliti belum mendapatkan data yang cukup, maka peneliti dapat mencari sampel lain sampai mendapatkan data yang cukup. Untuk melihat nilai tambah tiwul instan langsung melakukan wawancara dengan home industry KWT Tani Hidup.

Metode yang digunakan dalam penelitian ini adalah metode survei dengan menggunakan data primer dan sekunder. Data primer diperoleh melalui teknik wawancara (pengisian kuesioner) langsung dengan responden di Desa Wonosari Kecamatan Pekalongan Kabupaten Lampung Timur. Data sekunder bersumber dari beberapa lembaga/instansi terkait dalam penelitian ini seperti Dinas Pertanian Provinsi maupun Kabupaten, Biro Pusat Statistik (BPS) dan pihak terkait lainnya yang berhubungan dengan informasi pendataan.

Analisis data yang digunakan adalah Analisis SWOT, yakni metode untuk identifikasi berbagai faktor secara sistematis untuk merumuskan strategi yang diperlukan. Analisis didasarkan pada logika yang dapat memaksimalkan kekuatan (strengths) dan peluang (opportunities), namun secara bersamaan dapat meminimalkan kelemahan (weaknesses) dan 
ancaman (threats) (Rangkuti, 2008). Sedangkan untuk menganalisis nilai tambah mengunakan rumus Hayami et al, 1987.

Dalam melakukan identifikasi pengembangan usahatani, dari data yang diperoleh melalui survey di lapangan.Analisis SWOT dilakukan untuk mendapatkan alternatif-alternatif strategi pengembangan usahatani di Desa Wonosari Kecamatan Pekalongan Kabupaten Lampung Timur.Alat yang dipakai untuk menyusun faktor-faktor strategis adalah matrik SWOT.Matrik ini dapat menggambarkan secara jelas peluang dan ancaman eksternal yang dihadapi dapat disesuaikan dengan kekuatan dan kelemahan yang dimiliki.Analisis SWOT dilakukan dalam tiga tahap, yaitu pengumpulan data (input stage), analisis (matcing stage), dan pengambilan keputusan (decision stage). Setelah itu, dilakukan analisis nilai tambah dengan Metode Hayami. Prosedur perhitungan nilai tambah pengolahan dengan Metode Hayami seperti pada Tabel 3.

Tabel 3 Prosedur perhitungan nilai tambah menggunakan Metode Hayami

\begin{tabular}{llc}
\hline \multicolumn{1}{l}{ No } & \multicolumn{1}{c}{ Variabel } & Nilai \\
\hline \multicolumn{2}{l}{ Output, Input, dan Harga } & $(1)$ \\
1. & Output (kg) & $(2)$ \\
2. & Bahan Baku (kg) & $(3)$ \\
3. & Tenaga Kerja Langsung (HOK) & $(4)=(1) /(2)$ \\
4. & Faktor Konversi & $(5)=(3) /(2)$ \\
5. & Koefisien Tenaga Kerja Langsung $(\mathrm{HOK} / \mathrm{kg})$ & $(6)$ \\
6. & Harga Output (Rp/kg) & $(7)$ \\
7. & Upah Tenaga Kerja Langsung (Rp/HOK) & \\
\hline
\end{tabular}

Penerimaan dan Keuntungan

8. Harga Bahan Baku (Rp/kg)

9. Harga Input lain $(\mathrm{Rp} / \mathrm{kg})$

10. Nilai Output $(\mathrm{Rp} / \mathrm{kg})$

11. a. Nilai Tambah $(\mathrm{Rp} / \mathrm{kg})$

b. Rasio Nilai Tambah (\%)

$(10)=(4) \times(6)$

12. a. Pendapatan tenaga kerja Langsung $(\mathrm{Rp} / \mathrm{kg})$

$(11 \mathrm{a})=(10)-(8)-(9)$

b. Pangsa tenaga kerja langsung (\%)

13. a. Keuntungan $(\mathrm{Rp} / \mathrm{kg})$

b. Tingkat Keuntungan (\%)

$(11 \mathrm{~b})=(11 \mathrm{a}) /(10) \times 100$

$(12 a)=(5) \times(7)$

$(12 \mathrm{~b})=(12 \mathrm{a}) /(11 \mathrm{a}) \times 100$

$(13 a)=(11 a)-(12 a)$

$(13 b)=(13 a) /(10) \times 100$

Balas Jasa Pemilik Faktor Produksi

14. Marjin $(\mathrm{Rp} / \mathrm{kg})$

a. Pendapatan tenaga kerja langsung (\%)

b. Sumbangan input lain (\%)

c. Keuntungan perusahaan (\%)

$$
\begin{gathered}
(14)=(10)-(8) \\
(14 a)=(12 a) /(14) \times 100 \\
(14 b)=(9) /(14) \times 100 \\
(14 c)=(13 a) /(14) \times 100
\end{gathered}
$$

\section{Hasil dan Pembahasan}

\section{Analisis SWOT}

Menentukan faktor internal dan faktor eksternal untuk strategi pengembangan pemasaran tiwul instan di Desa Wonosari Kecamatan Pekalongan Kabupaten Lampung Timur. Analisis Faktor Internal dan Eksternal Menggunakan Matrik IFAS dan EFAS, dengan memasukan identifikasi kekuatan, kelemahan, peluang, dan ancaman. Kemudian diberi bobot dan peringkat maka diperoleh skor pembobotan.

Berdasarkan Tabel 4 menunjukkan bahwa hasil pengamatan matrik IFAS, faktor strategi internal yang merupakan kekuatan terbesar dan paling berpengaruh terhadap pemasaran tiwul instan di Desa Wonosari Kecamatan Pekalongan adalah kualitas produk yang dihasilkan 
memiliki bobot sebesar 0,18. Hal ini menunjukan bahwa apabila kualitas produk yang dihasilkan baik maka pengusaha tiwul instan di Desa Wonosari Kecamatan Pekalongan akan memperoleh pemasaran tiwul instan yang meningkat sehingga permintaan juga meningkat.

Table 4. Matrik Internal Faktor Analisysis Strategic (IFAS)

\begin{tabular}{lccc}
\hline Faktor-faktor Strategi Internal & Bobot & Rating & Skor Pembobotan \\
\hline Kekuatan & & & \\
- Melakukan pengembangan produk baru & 0,02 & 3,48 & 0,07 \\
- Pelayanan terhadap konsumen yang baik & 0,08 & 3,52 & 0,28 \\
- Kualitas produk yang dihasilkan & 0,18 & 3,52 & 0,63 \\
- Penjualan promosi/periklanan & 0,02 & 3,48 & 0,07 \\
- Kekuatan bisnis dan manajemen & 0,02 & 3,48 & 0,07 \\
- Lokasi pabrik & 0,12 & 3,28 & 0,39 \\
Total & $\mathbf{0 , 4 4}$ & $\mathbf{1 0 0}$ & $\mathbf{1 , 5 2}$ \\
\hline Kelemahan & & & \\
- Fasilitas pabrik seperti alat produksi & 0,02 & 3,48 & 0,07 \\
$\quad$ yang kurang memadai & 0,08 & 3,52 & 0,28 \\
- Saluran distribusi & 0,08 & 3,52 & 0,28 \\
- Proses produksi yang lama & 0,02 & 3,48 & 0,07 \\
- Persediaan modal & 0,02 & 3,48 & 0,07 \\
- Mutu produk & 0,02 & 3,48 & 0,07 \\
- Organisasi penjualan & $\mathbf{0 , 2 4}$ & $\mathbf{1 0 0}$ & $\mathbf{0 , 8 4}$ \\
\hline Total & & & \\
\hline
\end{tabular}

Sumber: Data primer, diolah

Faktor strategi internal yang merupakan kelemahan terbesar dan paling berpengaruh terhadap pemasaran tiwul instan di Desa Wonosari Kecamatan Pekalongan adalah saluran distribusi yaitu 0,08 dan proses produksi yang lama yakni 0,08 . Hal ini menunjukan bahwa saluran distribusi yang panjang mempengaruhi pendapatan pengusaha tiwul instan dan proses produksi yang lama mempengaruhi para konsumen untuk membeli tiwul instan. Hasil analisis matrik IFAS untuk kekuatan mendapatkan skor 1,52 dan kelemahan mendapatkan skor 0,84. Sehingga diperoleh total nilai pada posisi internal rata-rata yang dilihat dari bobot yaitu 2,36. Hal ini bahwa skor kekuatan pada pemasaran tiwul instan di Desa Wonosari Kecamatan Pekalongan lebih baik dari pada kelemahannya.

Berdasarkan penilaian skor yang telah disusun, total skor pemasaran tiwul instan di Desa Wonosari Kecamatan Pekalongan sebesar 2,36 termasuk dalam kategori baik, yaitu diatas rata-rata 2 dari rating yang telah ditetapkan maksimal 4. Kelemahan pemasaran tiwul instan di Desa Wonosari Kecamatan Pekalongan harus lebih diperhatikan agar nantinya bisa diperkecil. Dari hasil tersebut petani harus lebih bisa memanfaatkan kekuatan yang dimiliki untuk mengatasi kelemahan-kelemahannya. Adapun hasil perkalian antara rata-rata bobot dan rating dari petani digabungkan dalam matrik EFAS ditunjukan pada Tabel 5.

Berdasarkan Tabel 5 menunjukkan bahwa hasil perhitungan EFAS, faktor strategi ekternal yang merupakan peluang terbesar dan paling berpengaruh terhadap pemasaran tiwul instan di Desa Wonosari Kecamatan Pekalongan yaitu jumlah produksi dengan nilai bobot sebesar 0,57. Hal ini menunjukan bahwa jumlah produksi yang tinggi dapat meningkatkan pendapatan pengusaha tiwul instan.Karena jumlah produksi yang tinggi yakni dari permintaan baik agen ataupun konsumen yang telah menjadi langganan.

Faktor strategi eksternal yang merupakan ancaman terbesar dan paling berpengaruh terhadap pemasaran tiwul instan di Desa Wonosari Kecamatan Pekalongan adalah penetapan hargayang dilihat dari besarnya bobot yaitu 1,53. Penetapan harga dari tingkat produsen dapat menjadi ancaman bagi pengusaha tiwul dalam proses pemasaran di Desa Wonosari Kecamatan 
Pekalongan karena bagi pengusaha total biaya produksi yang tidak menentu menjadikan penetapan harga yang kurang adil bagi pengusaha. Hasil analisis matrik EFAS untuk peluang mendapatkan skor 4,91 ada ancaman mendapatkan skor 5,92. Sehingga diperoleh total nilai eksternal rata-rata yaitu sebesar 10,83. Hal ini berarti bahwa skor peluang yang dimiliki Pengusaha tiwul instan di Desa Wonosari Kecamatan Pekalongan lebih kecil dari pada ancamannya.

Table 5. Matrik Eksternal Faktor Analisysis Strategic (EFAS)

\begin{tabular}{lccc}
\hline Faktor-faktor Strategi Eksternal & Bobot & Rating & Skor Pembobotan \\
\hline Peluang & & & \\
- Pertumbuhan pasar & 0,07 & 3,23 & 0,23 \\
- Siklus penjulaan & 0,27 & 3,23 & 0,87 \\
- Jumlah produksi & 0,57 & 3,23 & 1,84 \\
- Pemasaran langsung & 0,17 & 3,23 & 0,55 \\
- Pemilihan merek dagang & 0,27 & 3,23 & 0,87 \\
- Respon konsumen terhadap promosi & 0,17 & 3,23 & 0,55 \\
$\quad$ yang digunakan & & & \\
\hline Total & $\mathbf{1 , 5 2}$ & $\mathbf{1 0 0}$ & $\mathbf{4 , 9 1}$ \\
\hline $\begin{array}{l}\text { Ancaman } \\
\text { - Ketersediaan sumberdaya (bahan baku) }\end{array}$ & 0,47 & 3,23 & 1,52 \\
- Isu politik/peraturan pemerintah & 0,07 & 3,23 & 0,23 \\
- Perubahan teknologi & 0,27 & 3,23 & 0,87 \\
- Penetapan harga & 1,53 & 0,17 & 0,26 \\
- Sarana transportasi dalam proses & 1,03 & 1,17 & 1,21 \\
$\quad$ pemasaran tiwul masyarakat & & & \\
- Hubungan $\quad$ dalam & 0,57 & 3,23 & 1,84 \\
$\quad$ menawarkan produk & & & \\
\hline Total & $\mathbf{3 , 9 4}$ & $\mathbf{1 0 0}$ & $\mathbf{5 , 9 2}$ \\
\hline
\end{tabular}

Sumber: Data primer, diolah

Berdasarkan penilaian skor yang telah disusun, total skor pemasaran tiwul instan di Desa Wonosari Kecamatan Pekalongan sebesar 10,83 termasuk kategori pemasaran tiwul instan di Desa Wonosari Kecamatan Pekalongankurang baik yaitu berada di atas rata-rata nilai 2 dari rating yang telah ditetapkan maksimal 4. Dengan demikian,pengusaha tiwul instan di Desa Wonosari Kecamatan Pekalongan harus memiliki antisipasi yang tinggi terhadap segala ancaman yang datang dengan memanfaatkan peluang yang dimiliki.

Kegunaan matrik IFAS dan EFAS adalah untuk mengetahui posisi pengusaha tiwul instan di Desa Wonosari Kecamatan Pekalongan saat ini. Oleh sebab itu pemetaan posisi pengusaha tiwul instan di Desa Wonosari Kecamatan Pekalongan sangat penting dalam pemilihan strategi yang ditetapkan. Berdasarkan hasil analisis yang telah dilakukan, total nilai pada metrik IFAS untuk kekuatan dan kelemahan sebesar 2,36, yang artinya faktor internal berada di atas rata-rata. Sedangkan total nilai pada matrik EFAS untuk peluang dan ancaman yaitu sebesar 10,83 yang artinya faktor eksternal berada di atas rata-rata.

Analisis SWOT digunakan untuk mengidentifikasi berbagai faktor untuk merumuskan strategi. Berdasarkan data faktor-faktor internal dan eksternal didapatkan skor pembobotan sebagai berikut : faktor kekuatan $=1,52$, faktor kelemahan $=0,84$, faktor peluang $=4,91$ dan faktor ancaman 5,92.

Analisis SWOT yang dilakukan sebelumnya dapat digunakan sebagai dasar dalam penentuan strategi pemasaranpengusaha tiwul instan di Desa Wonosari Kecamatan Pekalongan kedepan. SWOT matrik ini dibangun berdasarkan hasil analisis faktor-faktor strategis internal maupun eksternal yang terdiri dari berbagai faktor kekuatan, kelemahan, peluang dan ancaman. 
Hasil analisis pada matrik SWOT diperoleh koordinat $(0,34 ;-0,50)$ yang mana koordinat ini masuk pada kuadran II, yakni meskipun menghadapi berbagai ancaman, perusahaan ini masih memiliki kekuatan dari segi internal. Strategi yang harus diterapkan adalah menggunakan kekuatan untuk memanfaatkan peluang jangka panjang dengan cara strategi diversifikasi (produk/pasar). Pemasaran tiwul instan di Desa Wonosari Kecamatan Pekalongan memiliki kekuatan, sehingga dapat memanfaatkan kekuatan yang ada. Strategi yang harus diterapkan adalah mendukung kebijakan pertumbuhan agresif.
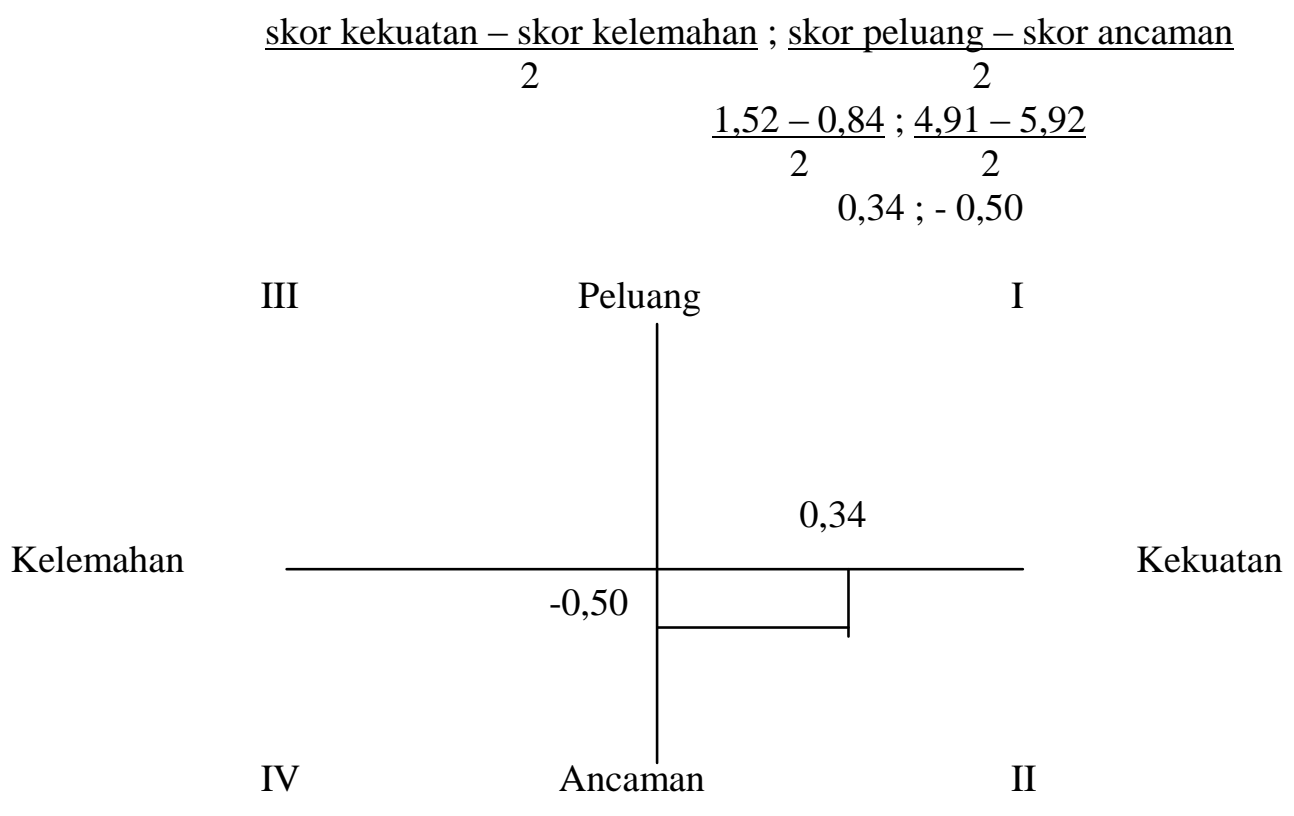

Gambar 1. Grafik Analisis SWOT Pengusaha Tiwul Instan di Desa Wonosari Kecamatan Pekalongan

\section{Perioritas Strategi Pengembangan Pemasaran dengan Analisis SWOT}

Hasil penggabungan perhitungan pembobotan rating IFAS dan EFAS dapat dilihat pada Tabel 6.

Tabel 6. Pembobotan rating IFAS dan EFAS

\begin{tabular}{ccc}
\hline & $\mathbf{O}=\mathbf{4 , 9 1}$ & $\mathbf{T}=\mathbf{5 , 9 1}$ \\
\hline $\mathbf{S}=\mathbf{1 , 5 2}$ & $\mathrm{SO}=6,43$ & $\mathrm{ST}=7,43$ \\
$\mathbf{W}=\mathbf{0 , 8 4}$ & $\mathrm{WO}=5,75$ & $\mathrm{WT}=6,75$ \\
\hline
\end{tabular}

Berdasarkan tabel 6 menunjukkan bahwa hasil pembobotan rating hasil kuesioner SWOT, maka dapat disusun prioritas strategi berdasarkan kombinasi strategi yang paling tinggi sampai dengan paling rendah, dapat dilihat pada Tabel 7.

Berdasarkan tabel 7 menunjukkan bahwa hasil interaksi IFAS dan EFAS yang menghasikan alternatif strategi yang mendapatkan bobot tertinggi adalah Strengh-Threat (ST dengan skor 7,43, diterjemahkan sebagai strategi yang menggunakan kekuatan untuk memanfaatkan peluang. Strategi untuk pemasaraan tiwul bobot kekuatan lebih besar dari pada kelemahan, sedangkan bobot peluang lebih besar daripada ancaman dalam pemasaran tiwul instan di Desa Wonosari Kecamatan Pekalongan.

Tabel 7. Tingkat Prioritas Strategi SWOT 


\begin{tabular}{ccc}
\hline Prioritas & Strategi & Bobot Nilai \\
\hline I & Strengh-Opportunity $(S O)$ & 6,43 \\
II & Strengh-Threat $(S T)$ & 7,43 \\
III & Weakness-Opportunity $(W O)$ & 5,75 \\
IV & Weakness-Threat $(W T)$ & 6,75 \\
\hline
\end{tabular}

Tujuan dari tahap analisis terhadap faktor-faktor strategi (matrik SWOT) adalah untuk menghasilkan alternatif strategi yang layak. Berdasarkan matrik SWOT dihasilkan srategi Strengh-Opportunity (SO), Strengh-Threats (ST), Weakness-Opportunity (WO), dan Weakness Threats $(W T)$. Hasil analisis terhadap empat strategi yang disarankan dapat dilihat pada Tabel 8.

Tabel 8. Matrik SWOT Pemasaran Tiwul Instan di Desa Wonosari Kecamatan Pekalongan

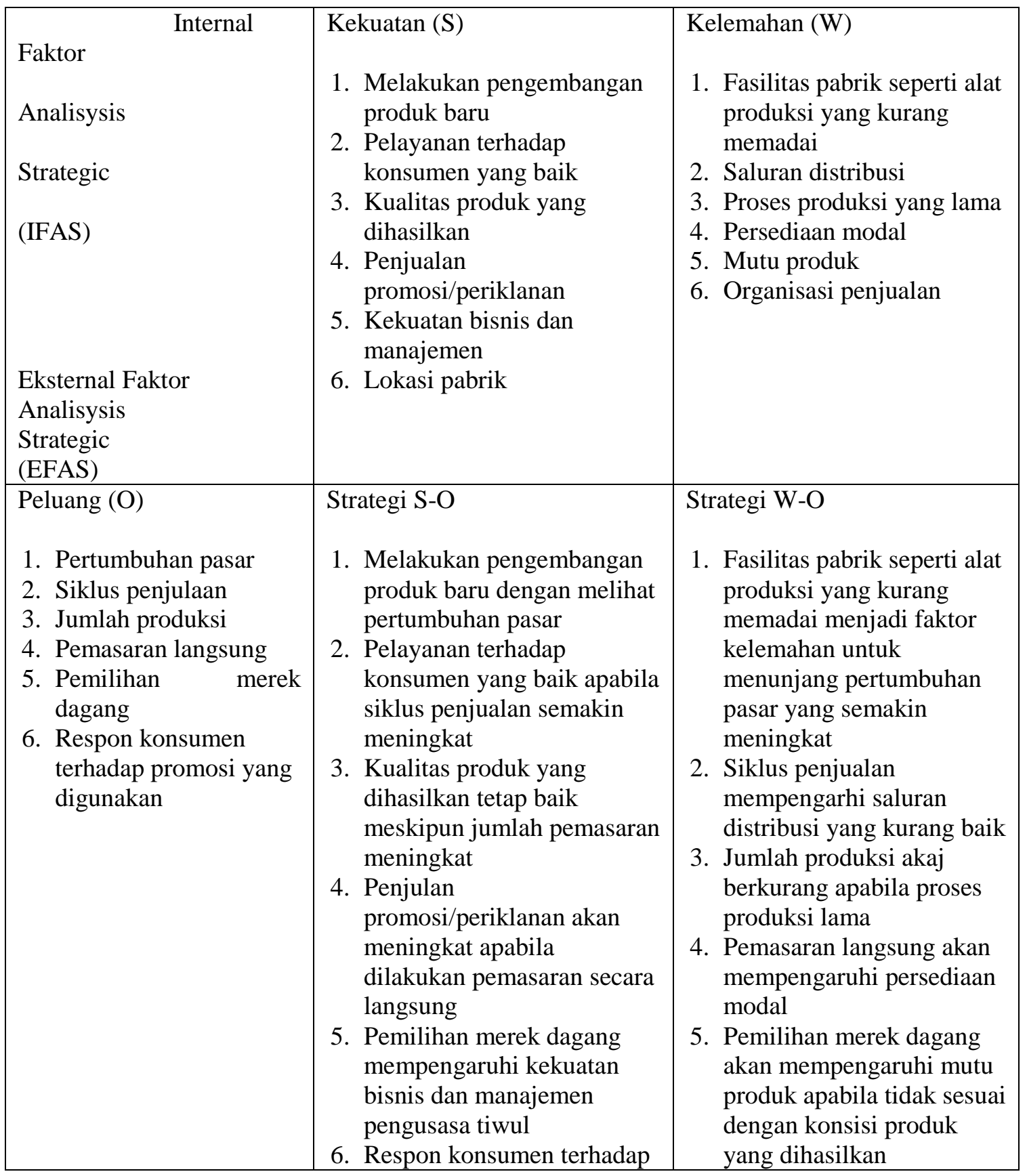




\begin{tabular}{|c|c|c|}
\hline & $\begin{array}{l}\text { promosi yang digunakan } \\
\text { mempengaruhi lokai pabrik } \\
\text { yang baik }\end{array}$ & $\begin{array}{l}\text { 6. Respon konsumen } \\
\text { terhadap promosi yang } \\
\text { digunakan berpengaruh } \\
\text { pada organisasi penjulaan }\end{array}$ \\
\hline Ancaman $(\mathrm{T})$ & Strategi S-T & Strategi W-T \\
\hline $\begin{array}{l}\text { 1. Ketersediaan } \\
\text { sumberdaya (bahan } \\
\text { baku) }\end{array}$ & $\begin{array}{l}\text { 1. Melakukan pengembangan } \\
\text { produk baru dengan melihat } \\
\text { kesederhanaan sumberdaya }\end{array}$ & $\begin{array}{l}\text { 1. Fasilitas pabrik seperti alat } \\
\text { produksi yang kurang } \\
\text { memadai menjadi faktor }\end{array}$ \\
\hline pemerintah & 2. Pelayanan terhadap & menunjang ketersediaan \\
\hline 3. Perubahan teknologi & konsumen yang baik & sumberdaya (bahan baku) \\
\hline 4. Penetapan harga & berpengaruh pada isu & 2. Isu politik/peraturan \\
\hline $\begin{array}{l}\text { 5. Sarana transportasi } \\
\text { dalam proses } \\
\text { pemasaran tiwul }\end{array}$ & $\begin{array}{l}\text { politik/peraturan pemerintah } \\
\text { 3. Kualitas produk yang } \\
\text { dihasilkan tetap baik }\end{array}$ & $\begin{array}{l}\text { pemerintah mempengarhi } \\
\text { saluran distribusi yang } \\
\text { kurang baik }\end{array}$ \\
\hline $\begin{array}{l}\text { 6. Hubungan masyarakat } \\
\text { dalam menawarkan } \\
\text { produk }\end{array}$ & $\begin{array}{l}\text { meskipun terdapat } \\
\text { perubahan teknologi } \\
\text { 4. Penjulan } \\
\text { promosi/periklanan akan } \\
\text { meningkat apabila } \\
\text { penetapan harga dapat stabil }\end{array}$ & $\begin{array}{l}\text { 3. Perubahan teknologiakan } \\
\text { mempengaruhi proses } \\
\text { produksi yang lama } \\
\text { 4. Penetapan harga akan } \\
\text { mempengaruhi persediaan } \\
\text { modal }\end{array}$ \\
\hline & $\begin{array}{l}\text { 5. Sarana transportasi dalam } \\
\text { proses pemasaran tiwul } \\
\text { akan mempengaruhi } \\
\text { kekuatan bisnis dan } \\
\text { manajemen pengusasa tiwul }\end{array}$ & $\begin{array}{l}\text { 5. Sarana transportasi dalam } \\
\text { proses pemasaran tiwul } \\
\text { akan mempengaruhi mutu } \\
\text { produk apabila tidak sesuai } \\
\text { dengan konsisi produk }\end{array}$ \\
\hline & $\begin{array}{l}\text { 6. Respon konsumen terhadap } \\
\text { promosi yang digunakan } \\
\text { mempengaruhi hubungan } \\
\text { masyarakat dalam } \\
\text { menawarkan produk }\end{array}$ & $\begin{array}{l}\text { yang dihasilkan } \\
\text { 6. Hubungan masyarakat } \\
\text { dalam menawarkan produk } \\
\text { berpengaruh pada } \\
\text { organisasi penjulaan }\end{array}$ \\
\hline
\end{tabular}

Sumber : Data primer, diolah

Berdasarkan tabel 8 menunjukkan hasil pembobotan nilai tertinggi adalah strategi Strengh-Threats $(S T)$ terletak pada kuadran II. Pada kuadran ini merupakan situasi yang sangat baik, karena pemasaran tiwul instan di Desa Wonosari Kecamatan Pekalongan memiliki kekuatan yang dimiliki pertanian untuk mengatasi ancaman. Tingginya strategi nilai prioritas ST bukan berarti strategi lain yang memiliki nilai lebih rendah tidak bermanfaat dan tidak perlu diterapkan. Akan tetapi, apabila ingin mendapatkan hasil yang maksimal strategi SO, WO, dan WT harus ikut dilaksanakan.

Strategi yang digunakan untuk meningkatkan pemasaran tiwul instan di Desa Wonosari Kecamatan Pekalongan adalah kualitas produksi tiwul instanagar konsumen meningkat maka pemasaran tiwul dapat dimanfaatkan oleh masyarakat dengan baik. Konsep yang baik akan memberikan pendapatan pengusaha tiwul tiwul instan. Dalam kondisi tersebut pengusaha tiwul instan mendapatkan pendapatan untuk produksi tiwul yang ada di Desa Wonosari Kecamatan Pekalongan.Strategi pemasaran tiwul instan yang dapat dilakukan adalah meningkatkan jumlah produksi dengan melakukan promosi melalui iklan atau media masa lainnya.

\section{Analisis Nilai Tambah}

Proses pengolahan tiwul instan merupakan proses yang diharapkan dapat memberikan nilai tambah terhadap komoditi pertanian. Besarnya nilai tambah yang diperoleh 
dihitung berdasarkan proses-proses produksi yang dilakukan. Rincian nilai tambah pada home industri dapat dilihat tabel 9.

Tabel 9. Nilai Tambah Tiwul Instan di Desa Wonosari Kecamatan Pekalongan

\begin{tabular}{|c|c|c|c|}
\hline \multicolumn{4}{|c|}{ No Variabel } \\
\hline \multicolumn{3}{|c|}{ Output,Input dan harga } & Jhothan Yenli \\
\hline 1 & Output (kg/produksi) & $\mathrm{A}$ & 450 \\
\hline 2 & Bahan baku (kg/produksi) & $\mathrm{B}$ & 250 \\
\hline 3 & Tenaga kerja (HOK/produksi) & $\mathrm{C}$ & 3.63 \\
\hline 4 & Faktor Konversi & $\mathrm{d}=\mathrm{a} / \mathrm{b}$ & 1.80 \\
\hline 5 & Koefisien Tenaga kerja & $\mathrm{e}=\mathrm{c} / \mathrm{b}$ & 0.01 \\
\hline 6 & Harga Output (Rp/kg) & $\mathrm{F}$ & 10.000 \\
\hline 7 & Upah Rata-rata Tenaga Kerja (Rp/HOK) & $\mathrm{G}$ & 60.000 \\
\hline \multicolumn{4}{|c|}{ Pendapatan dan Nilai Tambah $(\mathrm{Rp} / \mathrm{Kg})$} \\
\hline 8 & Harga bahan bahan baku & $\mathrm{H}$ & 550 \\
\hline 9 & Sumbangan input lain & I & 8.000 \\
\hline 10 & Nilai output & $j=d x f$ & 18.000 \\
\hline \multirow{2}{*}{11} & a.Nilai tambah & $k=j-h-i$ & 9.450 \\
\hline & b.Rasio Nilai tambah & $\mathrm{l}=\mathrm{k} / \mathrm{j}(\%)$ & 0.53 \\
\hline \multirow[t]{2}{*}{12} & a.Imbalan Tenaga Kerja & $\mathrm{m}=\mathrm{exg}$ & 871 \\
\hline & a.Bagian Tenaga Kerja & $\mathrm{n}=\mathrm{m} / \mathrm{k}(\%)$ & 0.09 \\
\hline \multirow[t]{2}{*}{13} & a.Keuntungan & $\mathrm{o}=\mathrm{k}-\mathrm{m}$ & 8.579 \\
\hline & b.Tingkat Keuntungan & $\mathrm{p}=\mathrm{o} / \mathrm{k}(\%)$ & 0.91 \\
\hline \multicolumn{4}{|c|}{ Balas Jasa untuk Faktor Produksi } \\
\hline & Margin & $q=j-h$ & 17.450 \\
\hline & a.Keuntungan & $\mathrm{r}=\mathrm{O} / \mathrm{q}(\%)$ & 0.49 \\
\hline & b.Tenaga Kerja & $\mathrm{s}=\mathrm{m} / \mathrm{q}(\%)$ & 0.05 \\
\hline & c.Input Lain & $\mathrm{t}=\mathrm{i} / \mathrm{q}(\%)$ & 0.46 \\
\hline
\end{tabular}

Sumber : Data primer, diolah

Berdasarkan Tabel 9 menunjukkan bahwa hasil produksi/output tiwul instan membutuhkan bahan baku (ubi kayu) dan tambahan input lain yaitu gula merah, garam dan air untuk proses produksi $450 \mathrm{~kg}$ dari jumlah bahan baku ubi kayu sebanyak $250 \mathrm{~kg}$ juga tambahan input lain $\mathrm{Rp} 8.000,00$ tetapi nilai tambah untuk produsen sebesar Rp 9.450,00. Dari pada harus menjual bahan baku secara langsung yang dalam $1 \mathrm{~kg}$ sebesar Rp.550. Nilai Tambah (NT >0) berarti pengembangan usaha tiwul instan memberikan nilai tambah.

\section{Simpulan dan Saran}

Strategi yang dapat dilakukan dalam pemasaran tiwul instan di Desa Wonosari Kecamatan Pekalongan Kabupaten Lampung Timur berdasarkan hasil analisis pada matrik SWOT diperoleh koordinat $(0,34 ;-0,50)$ yang mana koordinat ini masuk pada kuadran II, yakni meskipun menghadapi berbagai ancaman, perusahaan ini masih memiliki kekuatan dari segi internal. Strategi yang harus diterapkan adalah menggunakan kekuatan untuk memanfaatkan peluang jangka panjang dengan cara strategi diversifikasi (produk/pasar). Pemasaran tiwul instan di Desa Wonosari Kecamatan Pekalongan memiliki kekuatan yakni kualitas produksi tiwul dan meningkatkan jumlah produksi, yang dapat dimanfaatkan untuk menghadapi 
ancaman. Dan nilai tambah untuk produsen tiwul instan per produksi di Kabupaten Lampung Timur adalah Rp 9.450,00 sehingga akan meningkatkan pendapatan petani jika petani ubikayu melakukan pengolahan lebih lanjut dalam bentuk tiwul instan. Dengan meningkatkan kualitas produksi tiwul instan sehingga pemasaran tiwul instan dapat dimanfaatkan oleh masyarakat dengan baik tetapi juga harus memiliki inovasi baru untuk menjaga pemintaan sehingga meningkatkan penjualan dan pendapatan usaha tiwul instan akan lebih meningkat.

\section{Daftar Pustaka}

Badan Pusat Statistik Propinsi Lampung, 2015

Biro Pusat Statistik. 2012. Berita Resmi Statistik. www.bps.go.id

Boyd H, Walker O. C dan J.C. Larrenche. 2000. Manajemen Pemasaran : Suatu Pendekatan Strategis dengan Orientasi Global edisi Kedua. Erlangga : Jakarta.

Hayami Y. et al, 1987. Agricultural Marketing and Processing in upland Java a Perspective from a Sunda Village. Bogor: CGPRT Centre

Ibrahim dkk, 2003.Strategi Pembangunan Pertanian.Yogyakarta LABPERTA: Pustaka Utama.

Kotler P. 1992. Manajemen Pemasaran : Analisis, Perencanaan, Implementasi dan Pengendalian edisi ke Tujuh. Fakultas Ekonomi Univarsitas Indonesia: Jakarta.

Rangkuti, F. 2008. Strategi Promosi yang Kreatif dan Analisis Kasus Integrated Marketing

Communication. Jakarta : PT. GramediaPustakaUtama

Rukmana, Rahmat. 1998. Teknik Memproduksi Bibit Unggul Tanaman Buah-Buahan. $\neg$ Kanisius. Yogyakarta.

Soetarto, E.S., 2008. Petunjuk praktikum mikrobiologi untuk Mahasiswa fakultas biologi. Universitas Gadjah Mada, Yogyakarta.

Subahar, Tati. 2004. Khasiat \& Manfaat Pare si Pahit Pembasmi Penyakit. Jakarta, Agromedia Pustaka.

Sugiyono. 2009. Metode Penelitian Kuantitatif Kualitatif. CV.Alfabeta: Bandung.

Verawati N. 2011. Pengaruh Rasio Tepung Aren:Tepung Terigu dan Penambahan Baking Powder terhadap Sifat Fisik, Kimia dan Organoleptik Cookies. Universitas Brawijaya. Malang

Zulkarnain et al. 2010. Keunggulan Komparatif dan Kompetitif dalam Produksi Padi Di Kabupaten Lampung Tengah Propinsi Lampung. Jurnal Pertanian Terapan 10(3) : 185 199 